\title{
Paragonimus westermani metacercariae in two freshwater crab species in Kagoshima Prefecture, Japan, as a possible source of infection in wild boars and sika deer
}

\author{
Azusa BANZAI ${ }^{1,2)}$, Hiromu SUGIYAMA ${ }^{2) *}$, Mitsuko HASEGAWA ${ }^{2,3)}$, \\ Yasuyuki MORISHIMA ${ }^{2)}$ and Yasushi KAWAKAMI ${ }^{1) *}$ \\ 1)Laboratory of Environmental Biology, School of Life and Environmental Science, Azabu University, 1-17-71 \\ Fuchinobe, Chuo-ku, Sagamihara-shi, Kanagawa 252-5201, Japan \\ ${ }^{2)}$ Department of Parasitology, National Institute of Infectious Diseases, 1-23-1 Toyama, Shinjuku-ku, \\ Tokyo 162-8640, Japan \\ ${ }^{3)}$ Department of Parasitology, Institute of Tropical Medicine (NEKKEN), Nagasaki University, 1-12-4 Sakamoto, \\ Nagasaki-shi, Nagasaki 852-8523, Japan
}

J. Vet. Med. Sci.

83(3): 412-418, 2021

doi: 10.1292/jvms.20-0576

Received: 28 September 2020 Accepted: 27 December 2020 Advanced Epub:

19 January 2021
ABSTRACT. Paragonimiasis is a particular foodborne parasitic disease that is endemic to southern Kyushu, including Kagoshima Prefecture, Japan. We previously detected Paragonimus westermani triploid larvae in meat samples obtained from wild boars and sika deer hunted in Akune City, Kagoshima Prefecture. These mammals act as paratenic hosts and their meat is a source of human paragonimiasis. Paratenic host mammals and humans become infected with the lung fluke, $P$. westermani, following consumption of second intermediate hosts, freshwater crab species, namely, Geothelphusa dehaani or Sawagani in Japanese, and Eriocheir japonica or Mokuzugani in Japanese. Therefore, this study aimed to investigate the current infection status of $P$. westermani in freshwater crabs in Akune City. We collected freshwater crabs from 15 locations and found that the prevalence of $P$. westermani metacercariae was $1.6 \%$ for Sawagani (15 of 941 examined) and $22.1 \%$ for Mokuzugani ( 21 of 95 examined). Based on the morphological characterization of metacercariae and molecular analyses of the internal transcribed spacer 2 region and mitochondrial $16 \mathrm{~S}$ rRNA gene region using PCR-restriction fragment length polymorphism and sequencing, all metacercariae were identified as the triploid form of $P$. westermani. These results indicate that Sawagani and Mokuzugani serve as second intermediate hosts to maintain the life cycle of triploid $P$. westermani. Further, infection in crabs potentially leads to subsequent $P$. westermani infections in wild mammals, including wild boars and sika deer, both of which are considered important types of game meat in Japan.

KEY WORDS: foodborne disease, freshwater crab, game meat, lung fluke, Paragonimus westermani triploid form

Paragonimus westermani is one of the most critical helminths affecting both humans and carnivorous/omnivorous mammals. In Japan, this lung fluke species is present in 2 forms concerning chromosomal structure: the diploid and triploid forms [1]. Both forms infect humans; however, the resulting major respiratory symptoms developed in patients differ. Among patients infected with the triploid form, as adult flukes inhabit worm cysts formed in the lungs, chronic cough with rust-colored sputum is the most common symptom. Conversely, the diploid form generally causes pleural effusion without remarkable lesions in the lung parenchyma [12]. In mammals such as wild boars, which serve as paratenic hosts of both forms, most flukes remain in the larval stage within muscle tissues for an extended period while on their way to the pleural cavities [15]. Therefore, meat from paratenic hosts can be a source of infection in humans. Infection in humans through this route predominantly occurs in southern Kyushu due to the local food habit of consuming uncooked wild boar meat $[13,27]$. We previously investigated the contamination status of $P$. westermani in meat samples from regionally-hunted wild boars and sika deer obtained from a slaughtering and processing facility in Akune City, Kagoshima Prefecture, in southern Kyushu. Larvae of the P. westermani triploid form were detected in samples of sika deer as well as wild boars [26, 27]. Recently, the demand for such wild game meats has increased nationwide [10], which are referred to as "Jibie" in Japanese, based on the French word, "gibier". 
Paratenic host mammals and humans are infected with the $P$. westermani triploid form even through consumption of the second intermediate crab hosts, namely, the Japanese freshwater crab Geothelphusa dehaani, or Sawagani in Japanese, and the Japanese mitten crab Eriocheir japonica, or Mokuzugani in Japanese. Therefore, assessing the contamination status of these second intermediate hosts in Akune City is necessary to ensure food safety. Between 1960 and 1964, 41 Mokuzugani were captured, and 4 tested positive for Paragonimus metacercariae [8]. However, no epidemiological surveys for Paragonimus metacercariae have been conducted in intermediate host crabs thereafter. In this study, we collected Sawagani and Mokuzugani from rivers in Akune City and identified the isolated metacercariae at the species and form levels in accordance with their morphological and molecular characteristics. This study aimed to clarify the $P$. westermani metacercariae infection status of freshwater crabs, the consumption of which, as second intermediate hosts, potentially leads to infection in paratenic hosts.

\section{MATERIALS AND METHODS}

\section{Isolation and examination of Paragonimus metacercariae}

We manually collected Sawagani from 15 rivers in the central and southern parts of Akune City, Kagoshima Prefecture, from October 2014 to September 2019. We also captured Mokuzugani from 7 of the rivers, using crab traps, from August 2015 to September 2019 (Fig. 1). Crabs were individually examined using a previously described method [23] to obtain precise data regarding the prevalence and burden of Paragonimus metacercariae. Crabs were first immersed in ice-cold water for deep anesthesia through hypothermia. The carapace was then detached from the body. The gills and the internal organs, including the heart, midgut gland, gonad, and intestine, were dissected. These organs were compressed between 2 glass plates (10 cm $\times 6$ $\mathrm{cm}$ ) and examined for Paragonimus metacercariae using a stereoscopic microscope (SZX7; Olympus, Tokyo, Japan). To isolate metacercariae from the muscle tissues of the cephalothorax and legs, the tissues were minced in a meat grinder. Minced crab tissues were incubated with artificial gastric juice ( $0.1 \%$ pepsin, proteolytic activity $1: 10,000$, Nacalai Tesque, Inc., Kyoto, Japan, plus $0.7 \% \mathrm{HCl}$ ), and placed in a shaking incubator $(100 \mathrm{rpm})$ at $37^{\circ} \mathrm{C}$ for $3 \mathrm{hr}$. The digested material was filtered through a metal mesh sieve with a 1-mm pore size. The filtrate was transferred to a 1-1 measuring cylinder and allowed to stand for 30 min. The supernatant was aspirated out, and the sediment was transferred to a Petri dish to examine Paragonimus metacercariae under a stereoscopic microscope. Isolated metacercariae were placed on glass slides and pressed lightly under a coverslip for morphological observation and measurement using an optical microscope with a digital camera DP71 and imaging software cellSens (standard version 1.12; Olympus). Morphometric differences between the host groups, Sawagani and Mokuzugani, were compared using the Mann-Whitney $U$ test, and $P$-values less than 0.05 were considered statistically significant. Statistical analyses were performed using R (version 4.0.3 for Windows).
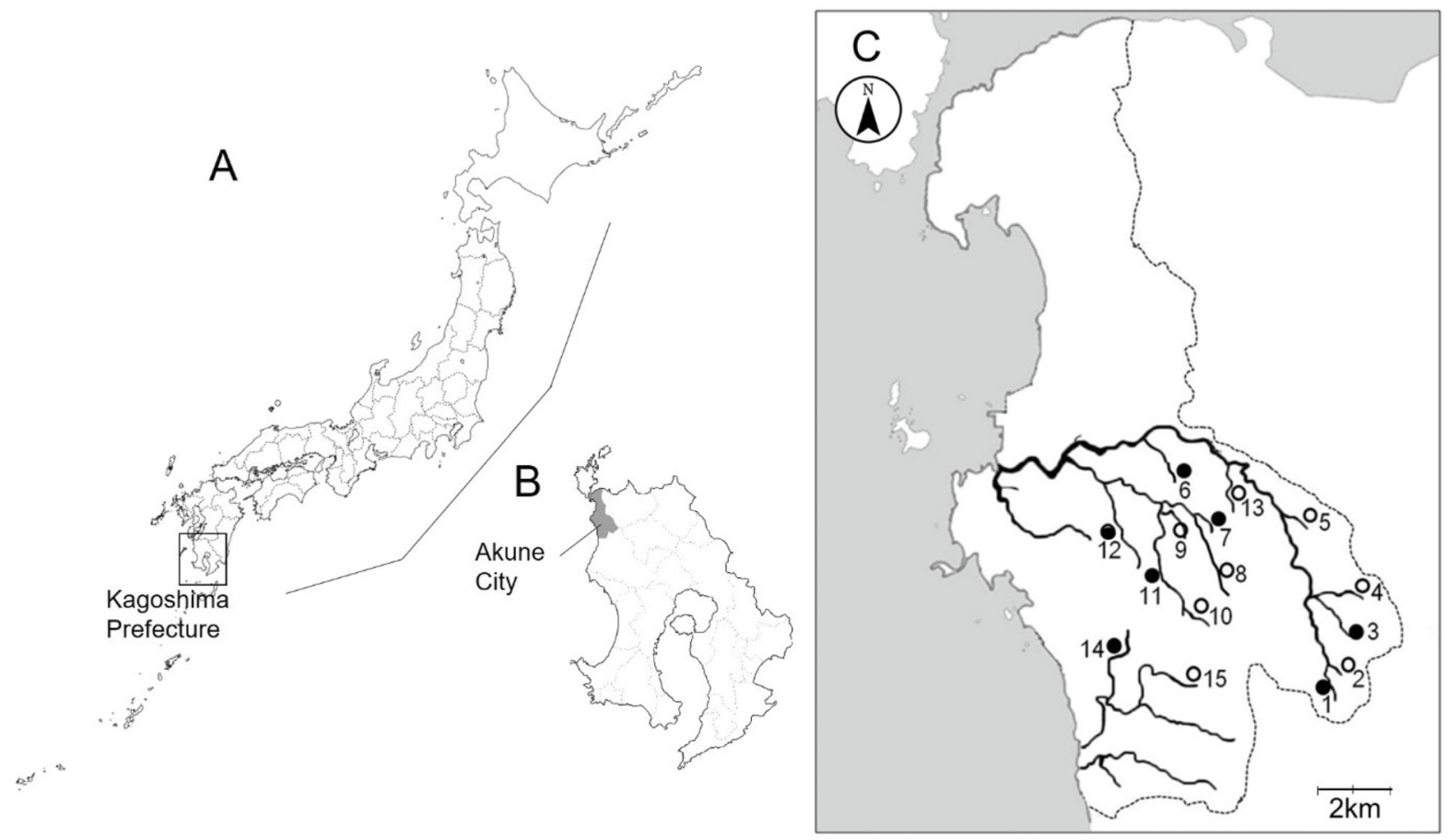

Fig. 1. Map of Japan (A) and Kagoshima Prefecture (B), showing the location where the present study was carried out. Map of Akune City (C) showing 15 locations where crabs were collected in the present study $(\bullet$, Locations where both Sawagani and Mokuzugani were collected; $\circ$, Locations where only Sawagani were collected). Numbers of the locations correspond to those shown in Tables 1 and 2. 


\section{DNA isolation, PCR-restriction fragment length polymorphism (RFLP) analysis, and sequencing}

Molecular typing of the isolated metacercariae was performed according to a previous report [25]. Briefly, DNA samples were extracted from individual metacercariae using the QIAamp DNA Micro Kit (Qiagen, Valencia, CA, USA) in accordance with the manufacturer's instructions. The internal transcribed spacer 2 (ITS2) region of the nuclear ribosomal RNA (rRNA) gene and the mitochondrial 16S rRNA gene region were then amplified via PCR using primer pairs $3 \mathrm{~S}$ (forward: 5'-GGTACCGGTGGATCACTCGGCTCGTG-3') with A28 (reverse: 5'-GGGATCCTGGTTAGTTTCTTTTCCTCCGC-3') and T7-1 (forward: 5'-ATTTACATCAGTGGGCCGTC-3') with SP6-1 (reverse: 5'-GATCCAAAAGCATGTGAAAC-3'), respectively. PCR amplification was conducted at a final volume of $50 \mu \mathrm{l}$ containing $2.5 \mu \mathrm{l}$ of template DNA, $2.5 \mathrm{U}$ of Phusion High-Fidelity DNA Polymerase (Thermo Fisher Scientific, Waltham, MA, USA), $0.25 \mu \mathrm{M}$ of each primer, and the manufacturer's HF reaction buffer. PCR amplification was performed using a thermal cycler (Takara PCR Thermal Cycler Dice Gradient; Takara Bio, Kusatsu, Japan), with 30 cycles at $98^{\circ} \mathrm{C}$ for $10 \mathrm{sec}, 55^{\circ} \mathrm{C}$ for $10 \mathrm{sec}$, and $72^{\circ} \mathrm{C}$ for $15 \mathrm{sec}$. Initial denaturation was carried out at $98^{\circ} \mathrm{C}$ for $30 \mathrm{sec}$, and final extension was carried out at $72^{\circ} \mathrm{C}$ for $7 \mathrm{~min}$. For RFLP analyses, we selected the restriction enzymes SnaBI and BsrDI. The former enzyme cleaved the ITS2 PCR products from $P$. westermani and the latter cleaved the PCR products of the mitochondrial $16 \mathrm{~S}$ rRNA gene region from the $P$. westermani triploid form [25]. The digested samples were electrophoresed on agarose gel $(3 \%, \mathrm{w} / \mathrm{v})$ and visualized using ethidium bromide to examine the cleavage pattern.

Undigested amplicons were sequenced using the corresponding primers to verify identification via RFLP analyses. The dye terminator method was performed using fluorescently-labeled di-deoxynucleotide triphosphates with the BigDye Terminator v 3.1 Cycle Sequencing Kit (Thermo Fisher Scientific) in accordance with the manufacturer's instructions. Nucleotide sequences were determined using a DNA sequencer (3730xl DNA Analyzer; Thermo Fisher Scientific), and their alignments were analyzed using GENETYX-Win, ver. 13 (GENETYX Co., Tokyo, Japan).

\section{RESULTS}

\section{Prevalence and intensity of Paragonimus metacercariae in crab hosts}

We collected Sawagani from 15 rivers in Akune City, whereas Mokuzugani were collected from 7 of the 15 rivers (Fig. 1). Both Sawagani and Mokuzugani tested positive for Paragonimus metacercariae from the Fujigadan, Yumikino, and Nomoto rivers (Tables 1 and 2). From the Kometsugi River and Yamashita River, we collected both Sawagani and Mokuzugani; however, only Mokuzugani tested positive for Paragonimus metacercariae. From Katahara River, we collected only Sawagani, which tested positive for Paragonimus metacercariae.

Among 941 Sawagani, $15(1.6 \%)$ tested positive for Paragonimus metacercariae, from which 24 metacercariae were detected (Table 1). The metacercariae-positive Sawagani were obtained from 4 out of the 15 rivers. The infection prevalence was the highest at $10.1 \%$ in Nomoto River (12 out of 119 Sawagani were positive for metacercariae); the lowest prevalence of $0.8 \%$ was observed in Sawagani from the Fujigadan River (1 out of 118 Sawagani was positive). The burden (total number of metacercariae detected/ number of Sawagani infected with Paragonimus metacercariae) was between 1 and 2 with a mean intensity of 1.6.

Of a total of 95 Mokuzugani examined, 21 (22.1\%) tested positive for Paragonimus metacercariae, among which 84

Table 1. Prevalence and number of Paragonimus metacercariae in Sawagani from Akune City, Kagoshima Prefecture

\begin{tabular}{|c|c|c|c|c|c|c|}
\hline \multirow{2}{*}{ Localities $^{1)}$} & \multicolumn{2}{|c|}{ No. of Sawagani } & \multirow{2}{*}{$\%$ infected } & \multirow{2}{*}{$\begin{array}{l}\text { Total no. of } \mathrm{mc}^{2)} \\
\text { detected }\end{array}$} & \multicolumn{2}{|c|}{ Intensity } \\
\hline & Examined & Infected & & & Range & Average \\
\hline 1. Kometsugi & 84 & 0 & & & & \\
\hline 2. Soutate & 32 & 0 & & & & \\
\hline 3. Ikenodan & 27 & 0 & & & & \\
\hline 4. Takamatsu & 13 & 0 & & & & \\
\hline 5. Kinzan & 44 & 0 & & & & \\
\hline 6. Yokote & 34 & 0 & & & & \\
\hline 7. Fujigadan & 118 & 1 & 0.8 & 1 & 1 & 1.0 \\
\hline 8. Chaengadan & 68 & 0 & & & & \\
\hline 9. Jijiro & 65 & 0 & & & & \\
\hline 10. Sashiki & 45 & 0 & & & & \\
\hline 11. Yamashita & 103 & 0 & & & & \\
\hline 12. Yumikino & 112 & 1 & 0.9 & 1 & 1 & 1.0 \\
\hline 13. Takashu & 29 & 0 & & & & \\
\hline 14. Nomoto & 119 & 12 & 10.1 & 21 & $1-2$ & 1.8 \\
\hline 15. Katahara & 48 & 1 & 2.1 & 1 & 1 & 1.0 \\
\hline Total & 941 & 15 & 1.6 & 24 & $1-2$ & 1.6 \\
\hline
\end{tabular}

1) Numbers of the localities correspond to those shown in Figs. 1 and 4.2) mc: metacercariae that were identified as the triploid form of Paragonimus westermani. 
metacercariae were detected (Table 2). The metacercariae-positive Mokuzugani were obtained from 5 of the 7 rivers. The highest prevalence was recorded in Nomoto River (100\%; only 1 Mokuzugani was captured, and it was positive), and the lowest prevalence was observed in Kometsugi river (3.6\%; 1 out of 28 Mokuzugani was positive). The burden was between 1 and 38 with a mean intensity of 4.0 .

\section{Morphology of the metacercariae detected in freshwater crabs}

The metacercariae isolated from the 2 species of freshwater crabs were almost spherical (Fig. 2). A large I-shaped excretory bladder filled with excretory granules was observed in the center of their bodies and a convoluted intestine surrounded both sides of the excretory bladder. A stylet was observed along the dorsal edge of the oral sucker. The diameter of the inner cyst wall of metacercariae from Sawagani $(n=6)$ was $393 \times 398$ to $499 \times 499 \mu$ m (mean: $435 \times 440 \mu \mathrm{m})$ and the thickness of the inner cyst wall was 12 to $20 \mu \mathrm{m}$ (mean: $16 \mu \mathrm{m}$; Fig. 2). The diameter of the inner cyst wall of metacercariae from Mokuzugani (n=50) was from $378 \times 382$ to $502 \times 522 \mu \mathrm{m}$ (mean: $412 \times 414 \mu \mathrm{m}$ ) and the thickness of the inner cyst wall was from 12 to $22 \mu \mathrm{m}$ (mean: $16 \mu \mathrm{m}$; Fig. 2). The differences in the mean size of metacercariae from the 2 crab species were not statistically significant (all $P>0.05$ ). Based on these key morphological features and the morphometric data, the metacercariae detected in the 2 species of freshwater crabs were presumed to be $P$. westermani. The only difference between metacercariae from the crab species was the presence or absence of red granules in the metacercarial body. Granules were observed in almost all metacercariae from Mokuzugani; however, red granules were never detected in those from Sawagani (Fig. 2).

\section{Molecular identification/typing of the metacercariae}

Species and form were identified using RFLP analysis of the PCR products amplified from metacercariae isolated from either Sawagani or Mokuzugani. ITS2 products of approximately $520 \mathrm{bp}$ were generated through PCR from all metacercarial DNA samples irrespective of host crab species (Fig. 3; lane 1). The amplicons were cleaved into 2 fragments (expected sizes for P. westermani of approximately 420 and 100 bp; Fig. 3; lane 2) through SnaBI digestion. The PCR products for the mitochondrial 16S rRNA gene region of approximately $840 \mathrm{bp}$ were also amplified from all metacercarial DNA samples irrespective of host crab species (Fig. 3; lane

Table 2. Prevalence and number of Paragonimus metacercariae in Mokuzugani from Akune City, Kagoshima Prefecture

\begin{tabular}{|c|c|c|c|c|c|c|}
\hline \multirow{2}{*}{ Localities $^{1)}$} & \multicolumn{2}{|c|}{ No. of Mokuzugani } & \multirow{2}{*}{$\%$ infected } & \multirow{2}{*}{$\begin{array}{l}\text { Total no. of } \mathrm{mc}^{2)} \\
\text { detected }\end{array}$} & \multicolumn{2}{|c|}{ Intensity } \\
\hline & Examined & Infected & & & Range & Average \\
\hline 1. Kometsugi & 28 & 1 & 3.6 & 2 & 2 & 2.0 \\
\hline 3. Ikenodan & 15 & 0 & & & & \\
\hline 6. Yokote & 1 & 0 & & & & \\
\hline 7. Fujigadan & 12 & 3 & 25 & 5 & $1-3$ & 1.7 \\
\hline 11. Yamashita & 28 & 15 & 53.6 & 38 & $1-14$ & 2.5 \\
\hline 12. Yumikino & 10 & 1 & 10 & 1 & 1 & 1.0 \\
\hline 14. Nomoto & 1 & 1 & 100 & 38 & 38 & 38 \\
\hline Total & 95 & 21 & 22.1 & 84 & $1-38$ & 4.0 \\
\hline
\end{tabular}

1) Numbers of the localities correspond to those shown in Figs. 1 and 4. 2) mc: metacercariae that were identified as the triploid form of Paragonimus westermani.
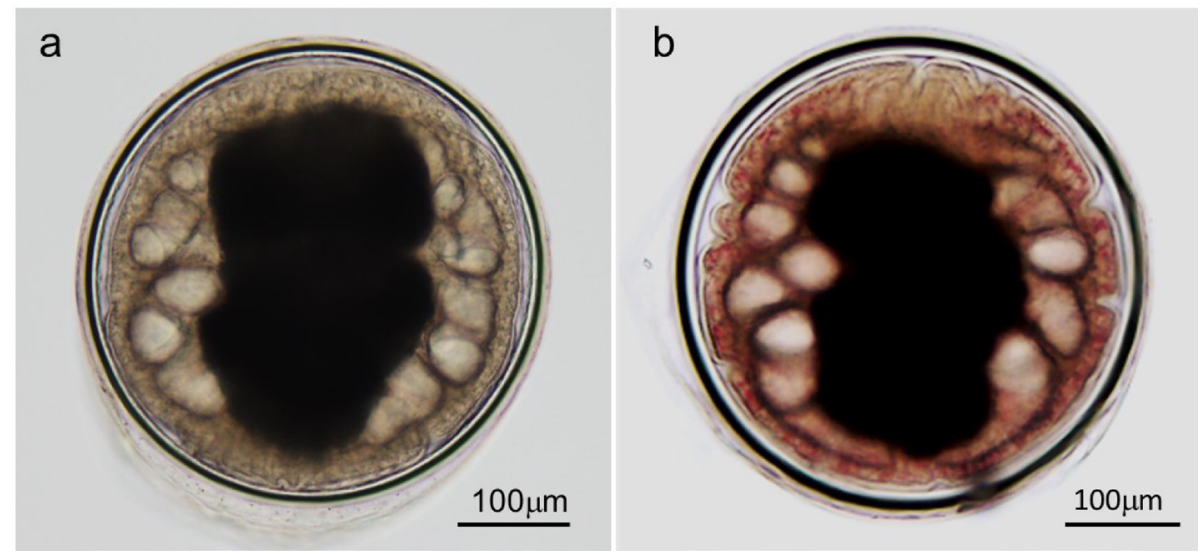

Fig. 2. Paragonimus metacercariae isolated from Sawagani (a) and Mokuzugani (b) captured in Akune City, Kagoshima Prefecture. Numerous minute red granules were evenly distributed throughout the bodies of the metacercariae isolated from Mokuzugani. 


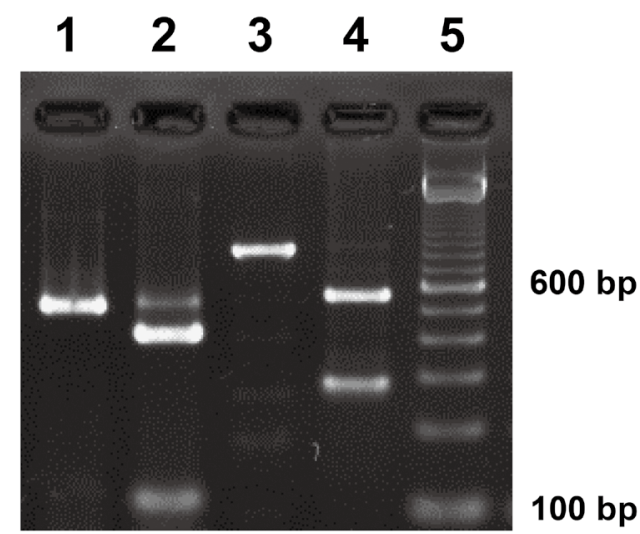

Fig. 3. Restriction fragment length polymorphism (RFLP) patterns of PCR products amplified from the DNA of Paragonimus metacercariae from Sawagani. The internal transcribed spacer 2 region of nuclear ribosomal DNA was amplified using PCR (lane 1) and treated with the restriction enzyme SnaBI (lane 2). The mitochondrial $16 \mathrm{~S}$ ribosomal RNA gene region was amplified (lane 3) and treated with the restriction enzyme BsrDI (lane 4). A 100-bp DNA ladder marker was used to estimate the size of fragments (lane 5). Based on PCR-RFLP patterns, we identified metacercariae as the triploid form of Paragonimus westermani. Metacercariae from Mokuzugani exhibited the identical cleavage pattern as those from Sawagani.
3). Amplicons were cleaved into 2 fragments through BsrDI digestion (expected sizes for the $P$. westermani triploid form of approximately 560 and $280 \mathrm{bp}$; Fig. 3 , lane 4). The digestion pattern was consistent with that of the triploid form of $P$. westermani. Accordingly, we used 5 metacercariae from Sawagani and 7 from Mokuzugani collected from all rivers where positive crabs were detected. We confirmed no variation in the RFLP patterns for any of the PCR amplicons.

Furthermore, we sequenced the undigested amplicons using the corresponding primers and revealed that the amplified products were of $463 \mathrm{bp}$ and $805 \mathrm{bp}$ for the ITS2 region and 16S rRNA gene region, respectively; primer sequences were not included. The sequences obtained in this study were identical to previously deposited sequences for the $P$. westermani triploid form (DDBJ/EMBL/GenBank accession numbers: LC577864 for ITS2 region and LC577863 for 16S rRNA gene region) from Japan. Therefore, the nucleotide sequences obtained in this study have been deposited in the DDBJ/EMBL/GenBank database as the metacercarial stage of the triploid form of $P$. westermani. The ITS2 region and 16S rRNA gene region sequences from Sawagani isolates were deposited under accession numbers LC578473 and LC578471, whereas those from Mokuzugani isolates were deposited under accession numbers LC578472 and LC578315.

\section{DISCUSSION}

The lung fluke, $P$. westermani, is a medically and veterinarily crucial foodborne helminth. This lung fluke species is widely distributed in East, Southeast, and South Asian countries, and comprises a species complex with extremely high genetic diversity in the ITS 2 region of rRNA gene, in particular $[23,31]$. However, $P$. westermani, or its species complex, can be readily identified through patterns of lobulation of ovary and the arrangement of cuticular spines on adult flukes. Recently, more localities with freshwater crabs positive for $P$. westermani metacercariae have been discovered, e.g., in Thailand [24] and Vietnam [3]; the morphological/molecular features of the isolated metacercariae were highly variable. These findings imply that existing molecular markers may not be versatile for identifying Paragonimus metacercariae as $P$. westermani. Under such circumstances, experimental infection studies are required to inoculate metacercariae in plausible definitive hosts, such as dogs or cats, so as to obtain gravid adults, which can then be used to identify the species as $P$. westermani or its species complex by anatomical characterization with solid taxonomic evidence [12]. In Japan, however, comparative studies have established associations between adult morphology and genetic characteristics observed at various life cycle stages among the lung flukes of the genus Paragonimus at the species/subspecies and form levels [16, 25]. Therefore, we identified the isolated metacercariae from both Sawagani and Mokuzugani collected from rivers in the central and southern parts of Akune City, Kagoshima Prefecture, as the triploid form of $P$. westermani based on their morphological and molecular characteristics. Red granules observed in the bodies of the metacercariae isolated from Mokuzugani. These granules probably developed during the growth process of larvae in the second intermediate crab host, Mokuzugani [12].

Akune City is in the Hokusatsu region in the northern part of the Satsuma Peninsula, along with 5 other neighboring municipalities, namely, Isa City, Izumi City, Satsumasendai City, Satsuma Town, and Nagashima Town. This region has long been recognized as endemic for human paragonimiasis $[8,19]$. Intensive field surveys have been performed to clarify the infectivity and prevalence of $P$. westermani metacercariae in second intermediate crab hosts in the region. Regarding Mokuzugani, surveys were previously conducted in Akune City [8], Sendai City (currently Satsumasendai City, the city/town name was changed following a municipal merger) [18], and Izumi City [19]. These field surveys all detected metacercariae of $P$. westermani. Sawagani were also previously collected in Kedouin Town (currently Satsumasendai City), in which the triploid P. westermani metacercariae were detected [20]. Miyazaki [12] reported that the triploid form of $P$. westermani metacercariae was primarily detected in Mokuzugani with a few exceptional locations in Kagoshima Prefecture, where the triploid form of metacercariae was detected in Sawagani [5, 20]. In the current study, we detected metacercariae of triploid $P$. westermani in both Sawagani and Mokuzugani in 3 rivers, and metacercariae were detected in only Sawagani in 1 river. It is plausible that the life cycle of triploid $P$. westermani is maintained in either Sawagani or Mokuzugani, or both, as the second intermediate hosts, with the triploid form of $P$. westermani accounting for the major cause of human paragonimiasis in this region.

Wild boars harbor $P$. westermani larvae in their muscles and play an important role as a source of infection in humans [13, 15]. Paragonimiasis cases were also reported following venison consumption in accordance with the dietary history revealed by patients $[13,17,32,33]$. The triploid form $P$. westermani larvae have been previously detected in the muscles of sika deer hunted and processed in a facility in Akune City [26]. Moreover, Sawagani exoskeleton has been reported in the stomach contents of sika deer in central Japan [9]. Therefore, it is reasonable to consider sika deer as a paratenic host of $P$. westermani. Indeed, the importance of 


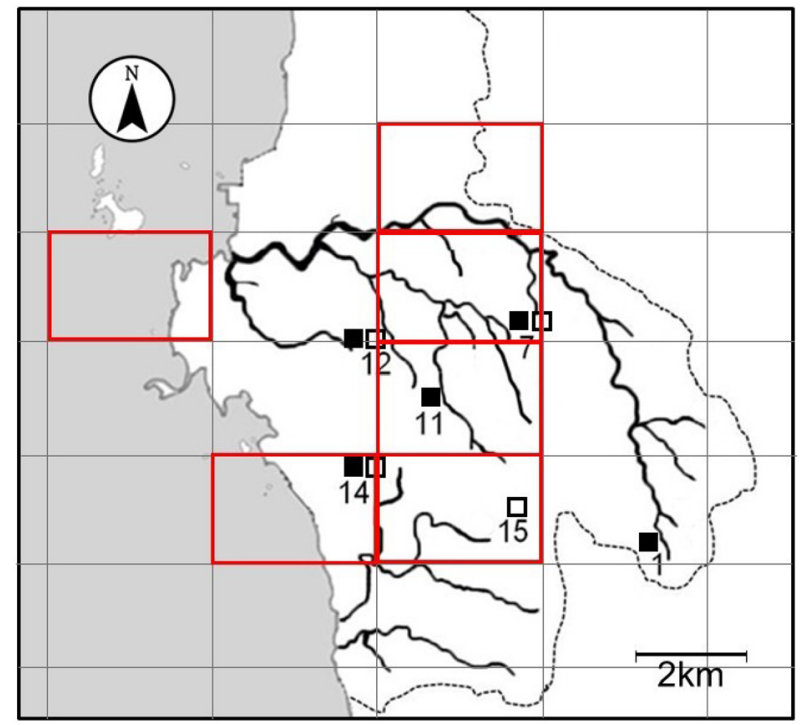

Fig. 4. The $2 \mathrm{~km} \times 3 \mathrm{~km}$ mesh map of the central and southern parts of Akune City showing the locations where Paragonimus westermani-positive crabs were collected in the present study ( $\square$, Locations where triploid $P$. westermani-positive Sawagani were collected; $\square$, Locations where triploid $P$. westermani-positive Mokuzugani were collected). Numbers of the locations correspond to those shown in Tables 1 and 2. The original mesh map encompassing Japan was drawn by Dainihon Ryoyukai, the Japan hunters' association, and we were approved to trace the map of Akune City for this manuscript. Red-bordered squares on this map designate areas where $P$. westermani-positive wild boars and sika deer were hunted $[26,27]$. venison as a source of infection has been highlighted [31, 33]. Wild boar and sika deer meat from the facility in Akune City is always provided after freezing at $-27^{\circ} \mathrm{C}$ for more than $24 \mathrm{hr}$; we retrieved the meat samples for inspection without freezing as an exception, and then isolated living Paragonimus larvae [26, 27]. Deep freezing of the meat can kill $P$. westermani larvae [7] and effectively prevent human infections if the meat was contaminated with $P$. westermani. However, we should be cautious that treatment such as deep freezing may not necessarily inactivate certain foodborne pathogens, e.g., Salmonella bacteria [22] and hepatitis E virus [29].

We consider the possibility that wild boars and sika deer hunted in Akune City become infected with $P$. westermani by feeding on Sawagani and Mokuzugani. A map shown in Fig. 4 indicates the hunting areas of $P$. westermani-infected mammals and the collection sites of $P$. westermani-positive crabs. Hunting areas and collection sites appear to correlate well geographically. The home range of wild boars is considered to be relatively small in relation to the large body size of the animal [21]. Wild boars are believed to inhabit small areas for long periods, provided that there is an adequate food supply and a low risk of predators [14]. Sika deer also roam within a small home range in warm regions such as Kyushu [30]. In the Hokusatsu Forest Planning Area located in the northern region of Kagoshima Prefecture, sika deer were tracked using GPS telemetry, and daily roaming distance was estimated to be as low as $0.8-1.2 \mathrm{~km}$ [4]. Since both wild boars and sika deer inhabit a limited habitat, they may become infected with $P$. westermani via ingestion of infected crabs in or around this study area. However, to confirm the hypothesis, collaborative studies are needed to determine the home range via a tracking survey of wild boars and sika deer living in the Hokusatsu region, particularly in Akune City. It is also necessary to analyze food consumption by these mammals.

In Japan, the former Cabinet implemented the "Growth Strategy 2017", which proposed the effective use of meat from

wild birds and beasts as game meat to support local economies [2]. The Ministry of Agriculture, Forestry and Fisheries supports the Cabinet policy and has selected several areas as Japan's pioneer models to facilitate the provision of safer and higher-quality game meat [10]. The Ministry of Health, Labour and Welfare has established guidelines for food safety management throughout the entire process from hunting to the consumption of game meat, to prevent food poisoning [11]. In brief, the initiative to secure safe game meat is gaining momentum and has currently received increasing attention in Japan. Traditionally, meat from wild birds and beasts has been consumed primarily by hunters and their families. However, more recently, opportunities for the consumption and distribution of game meat over a wider area have increased through promoting campaigns and online sales [6, 10, 28]. To prevent paragonimiasis outbreaks on the national level, governmental agencies for public health should accelerate the spread of information describing the need to cook wild boar and sika deer meat sufficiently before consumption, e.g., at $75^{\circ} \mathrm{C}$ for 1 min in the innermost region [11].

In conclusion, we identified the metacercariae as the triploid form of $P$. westermani that were isolated from Sawagani and Mokuzugani collected in Akune City, Kagoshima Prefecture. The triploid form of $P$. westermani larvae have been detected in the muscles of wild boars and sika deer hunted and processed in this city [26, 27]. These paratenic host mammals might become infected with triploid $P$. westermani through consumption of infected Sawagani or Mokuzugani in Akune City or the surrounding area. Studies are, therefore, required to assess the contamination status of Sawagani and Mokuzugani in Japan, as crab infection potentially leads to subsequent $P$. westermani infection of wild mammals, such as wild boars and sika deer. Furthermore, security safeguards should be constituted against $P$. westermani infections through the persistent health education campaigns for people who consume uncooked game meats or freshwater crabs.

POTENTIAL CONFLICT OF INTEREST. The authors have nothing to disclose.

ACKNOWLEDGMENTS. This study was financially supported in part by a grant from the Ministry of Health, Labour and Welfare (MHLW; H27-shokuhin-ippan-011 and H30-shokuhin-ippan-004) and a research grant from the Japan Agency for Medical Research and Development (AMED; 20fk0108136j0101). 


\section{REFERENCES}

1. Blair, D., Xu, Z. B. and Agatsuma, T. 1999. Paragonimiasis and the genus Paragonimus. Adv. Parasitol. 42: 113-222. [Medline] [CrossRef]

2. Cabinet Office. 2017. Investments for the future strategy 2017-Reforms to achieve Society 5.0. (Initiatives and Programs) (in Japanese). https:// www5.cao.go.jp/keizai-shimon/kaigi/minutes/2017/0609/shiryo 03-2.pdf [accessed on September 6, 2020].

3. Doanh, N. P., Tu, A. L., Bui, T. D., Loan, T. H., Nonaka, N., Horii, Y., Blair, D. and Nawa, Y. 2016. Molecular and morphological variation of Paragonimus westermani in Vietnam with records of new second intermediate crab hosts and a new locality in a northern province. Parasitology 143: 1639-1646. [Medline] [CrossRef]

4. Forestry Agency. 2018. Report on the emergency response project for forestry damage by sika deer (surveys of sika deer behavior and support for hunters) (The Hokusatsu Forest Planning area) (in Japanese). https://www.rinya.maff.go.jp/j/hogo/higai/attach/pdf/tyouju-67.pdf [accessed on September 6, 2020].

5. Habe, S. and Terasaki, K. 1982. On the type of Paragonimus westermani from crab hosts in Yaku Island, Kagoshima Prefecture. Jpn. J. Parasitol. 31: 27-32 (in Japanese with English abstract).

6. Kadohira, M., Phiri, B. J., Hill, G., Yoshizaki, R. and Takai, S. 2019. Game meat consumption and foodborne illness in Japan: a web-based questionnaire survey. J. Food Prot. 82: 1224-1232. [Medline] [CrossRef]

7. Kim, T. I., Oh, S. R., Dai, F., Yang, H. J., Ha, S. D. and Hong, S. J. 2017. Inactivation of Paragonimus westermani metacercariae in soy saucemarinated and frozen freshwater crabs. Parasitol. Res. 116: 1003-1006. [Medline] [CrossRef]

8. Kokuto, T. 1964. Studies on human paragonimiasis in Kagoshima Prefecture. Med. J. Kagoshima Univ. 16: 192-231 (in Japanese with English abstract).

9. Matsuo, K., Moribe, J., Takashima, Y., Kasuya, S., Yoshida, A., Abe, N., Saijuntha, W. and Agatsuma, T. 2018. Possibility of paragonimiasis due to consumption of raw deer meat. J. Jpn. Vet. Med. Assoc. 71: 449-453 (in Japanese with English abstract).

10. Ministry of Agriculture, Forestry and Fisheries. 2019. Summary of the annual report on food, agriculture and rural areas in Japan FY 2018. https:// www.maff.go.jp/e/data/publish/attach/pdf/index-160.pdf [accessed on September 13, 2020].

11. Ministry of Health, Labour and Welfare. 2020. Partial amendments to game meat sanitary control guidelines. Notification seishoku-hatsu No.05282 (in Japanese). https://www.mhlw.go.jp/content/11130500/000635324.pdf [accessed on September 13, 2020].

12. Miyazaki, I. 1991. Trematode zoonoses. 10. Paragonimiasis. pp. 76-146. In: An Illustrated Book of Helminthic Zoonoses (Miyazaki, I. ed.), International Medical Foundation of Japan, Tokyo.

13. Nagayasu, E., Yoshida, A., Hombu, A., Horii, Y. and Maruyama, H. 2015. Paragonimiasis in Japan: a twelve-year retrospective case review (2001-2012). Intern. Med. 54: 179-186. [Medline] [CrossRef]

14. Nakatani, J. 2006. Ecology and wildlife management of wild boar. Plant Protec. 60: 55-58 (in Japanese).

15. Nishida, H. and Shibahara, T. 2003. Epidemiology of paragonimiasis. pp. 201-217. In: Progress of Medical Parasitology in Japan, vol. 8 (Otsuru, M., Kamegai, S. and Hayashi, S. eds.), Meguro Parasitological Museum, Tokyo.

16. Ohari, Y., Suzuki, Y., Shibahara, T. and Itagaki, T. 2019. First report of Paragonimus skrjabini miyazakii metacercariae in Geothelphusa dehaani (Sawagani) occurring in Iwate Prefecture, Japan. J. Vet. Med. Sci. 81: 1109-1112. [Medline] [CrossRef]

17. Ohuchi, M., Inoue, S., Ozaki, Y., Fujita, T., Ueda, K. and Hanaoka, J. 2014. A case of Paragonimus westermani infection caused by eating raw deer meat. Jpn. J. Chest Surg. 28: 170-176 (in Japanese with English abstract). [CrossRef]

18. Okabe, K., Matsuse, M., Kamo, M., Ono, N., Shimomura, M., Tanaka, T., Ito, M. and Kawahara, H. 1957. Paragonimiasis in Kyushu. J. Kurume Med. Assoc. 20: 653-658 (in Japanese with English abstract).

19. Otsuji, Y. 2003. Paragonimiasis. pp. 183-200. In: Progress of Medical Parasitology in Japan, vol. 8 (Otsuru, M., Kamegai, S. and Hayashi, S. eds.), Meguro Parasitological Museum, Tokyo.

20. Sato, A., Uchikawa, R., Noda, S., Niiyama, T. and Miyazaki, I. 1982. On the Paragonimus westermani found from the freshwater crab, Geothelphusa dehaani, in the northern part of Kagoshima Prefecture. Jpn. J. Parasitol. 31 Suppl: 8 (in Japanese).

21. Spitz, F. 1992. General model of the spatial and social organization of the wild boars. pp. 385-389. In: Ongulés/Ungulates 91 (Spitz, F., Janeau, G., Gonzales, G. and Aulagnier, S. eds.), Société Française pour l'Etude et la Protection des Mammifères, Toulouse.

22. Sudo, K. 1988. Food poisoning caused by Salmonella following ingestion of raw venison sashimi. Food Hyg. Saf. Sci 29: 346-347 (in Japanese). [CrossRef]

23. Sugiyama, H., Singh, T. S. and Rangsiruji, A. 2013. Paragonimus. pp. 421-433. In: Molecular Detection of Human Parasitic Pathogens (Liu, D. ed.), CRC Press, London.

24. Sugiyama, H., Morishima, Y., Binchai, S., Rangsiruji, A. and Ketudat, P. 2007. New form of Paragonimus westermani discovered in Thailand: morphological characteristics and host susceptibility. SE. Asian J. Trop. Med. Pub. Health 38 Suppl. 1: 87-91.

25. Sugiyama, H., Umehara, A., Morishima, Y., Yamasaki, H. and Kawanaka, M. 2009. Detection of Paragonimus metacercariae in the Japanese freshwater crab, Geothelphusa dehaani, bought at retail fish markets in Japan. Jpn. J. Infect. Dis. 62: 324-325. [Medline]

26. Sugiyama, H., Shibata, K., Kawakami, Y., Gokuden, M., Morishima, Y. and Yamasaki, H. 2016. Assessing the potential risk of wild animal meat as a source of infection of paragonimiasis. Clin. Parasitol. 27: 40-42 (in Japanese).

27. Sugiyama, H., Shibata, K., Kawakami, Y., Arakawa, K., Morishima, Y., Yamasaki, H., Gokuden, M., Iwakiri, T. and Fukumori, J. 2015. Paragonimiasis due to the consumption of wild boar meat in Japan: contamination levels of lung fluke larvae in muscle samples of wild boars caught in Kagoshima Prefecture. Jpn. J. Infect. Dis. 68: 536-537. [Medline] [CrossRef]

28. Tasaki, Y., Wang, Y. and Kobayashi, S. 2011. The present situation and problems of e-commerce of venison. J. Jpn. Deer Stud. (2) 8-14 (in Japanese).

29. Tei, S., Kitajima, N., Takahashi, K. and Mishiro, S. 2003. Zoonotic transmission of hepatitis E virus from deer to human beings. Lancet 362: 371-373. [Medline] [CrossRef]

30. Yabe, T. and Takatsuki, S. 2009. Migratory and sedentary behavior patterns of sika deer in Honshu and Kyushu, Japan. pp. 273-283. In: Sika Deer: Biology and Management of Native and Introduced Populations (McCullough, D.R., Takatsuki, S. and Kaji, K. eds.), Springer, Tokyo.

31. Yoshida, A., Doanh, P. N. and Maruyama, H. 2019. Paragonimus and paragonimiasis in Asia: an update. Acta Trop. 199: 105074. [Medline] [CrossRef]

32. Yoshida, A., Tanaka, R., Kikuchi, T., Nagayasu, E. and Maruyama, H. 2016. Re-evaluation of the source of infection of paragonimiasis in Japan. Clin. Parasitol. 27: 49-51 (in Japanese).

33. Yoshida, A., Matsuo, K., Moribe, J., Tanaka, R., Kikuchi, T., Nagayasu, E., Misawa, N. and Maruyama, H. 2016. Venison, another source of Paragonimus westermani infection. Parasitol. Int. 65: 607-612. [Medline] [CrossRef] 